\title{
Changes in Anatomical Features of Chromolaena Odorata during Phytoaccumulation of Heavy Metals
}

\author{
Omoregie G. O. ${ }^{1,3, *}$ and Ikhajiagbe B. ${ }^{2,3,4}$ \\ ${ }^{1}$ Department of Environmental Management and Toxicology, Fed. Univ. of Petroleum Resources, Effurun, \\ Nigeria \\ ${ }^{2}$ Department of Plant Biology and Biotechnology, University of Benin, Benin City, Nigeria \\ ${ }^{3}$ Environmental Biotechnology and Sustainability Research Group, Department of Plant Biology and \\ Biotechnology, University of Benin, Nigeria \\ ${ }^{4}$ Applied Environmental Biosciences and Public Health Research Group, Department of Microbiology, \\ University of Benin, Nigeria \\ Corresponding Author: *omoregie.gloria@fupre.edu.ng
}

https://doi.org/10.36263/nijest.2021.02.0285

\begin{abstract}
The present study investigated the accumulation of selected HMs by Chromolaena odorata and the concomitant effects on leaf anatomical features. Top soils were collected from a marked plot and pooled together to obtain a composite sample. The soil was sun-dried to constant weight and measured into experimental pots at 20kg each). The pots were divided into 5 metal groups with 3 sub-groups each. Each group was polluted with Manganese (Mn), Cadmium $(\mathrm{Cd})$, Copper $(\mathrm{Cu})$, Lead $(\mathrm{Pb})$ and Zinc $(\mathrm{Zn})$ in their respective chloride forms. Concentrations of the metals in the soil were initially based on their respective ecological screening value/benchmark (ESV). The ESV values for the $5 \mathrm{HMs}$ were 50, 4, 100, 50 and $50 \mathrm{mg} / \mathrm{kg}$ respectively. Within each group, the respective HMs was applied in 3 concentrations of $1 E S V, 3 E S V$ and $5 E S V$. The control experiment consisted of plants grown in soils with no exogenous application of the test metals. The experiment was triplicated. Twenty hours later, equal sized stem cuttings of $C$. odorata $(2.0-2.3 \mathrm{~cm}$ in thickness, $30 \mathrm{~cm}$ in length) were planted per experimental pot. Six months later, results showed significant accumulation of metals in plant stem, leaves, and most especially the root. Mn was the most accumulated HM in all plant parts $(9.22$ - $17.86 \mathrm{mg} / \mathrm{kg})$, compared to $\mathrm{Cd}(0.85-1.66$ $\mathrm{mg} / \mathrm{kg}$ ).Significant changes in folial anatomy were reported in HM-impacted plants compared to the control. There were more upper epidermal stomata $\left(270-353 \mathrm{~mm}^{2}\right)$ in Mn-exposed plants compared to the others. Increase in vascular bundle thickness $(p<0.01)$ was reported in HMexposed plants compared to control. Highly significant decrease in stem parenchyma thickness $(p<0.01)$ never the less parenchyma thickness of HM-exposed plants ranged from $46.37-49.53 \mu \mathrm{m}$ in $\mathrm{Zn}$ and Pb-exposed plants compared to $79.23 \mu \mathrm{m}$ in the control.
\end{abstract}

Keywords: Chromolaena odorata, Ecological screening value, Anatomy, Heavy metal, Phytotoxicity, Ecophysiology

\subsection{Introduction}

The impact of toxicity of heavy metals on plants has been known to be far-reaching. These effects include significant changes in plant morphology, anatomy, physiology or biochemistry, which eventually result in either a decrease in the plant's exposure to the stressor(s) and/or limit damage and enable repair of compromised plant systems. When plants were exposed to higher concentrations of cadmium, the physiological impact was a significant impairment of calcium equilibrium, which inadvertently resulted in impairment of cell wall elasticity and cell redox balances (Perfus-Barbeoch et al., 2002). The significant interference of heavy metals in plant metabolism has long-term consequences for plant anatomical and developmental patterns (Akhil and Subhan, 1997; Bhandari and Mukhopadhyay, 1997; Maruthi Sridhar et al., 2005; Katayama et al., 2013). 
Heavy metal effects on plant anatomy are very important particularly given their role in photosynthesis and other important plant processes. The major concern therefore is the consequences these anatomical changes would present on plants that are used in the remediation of heavy metalcontaminated systems (Li et al., 2006; Katayama et al., 2013). Much as the efficiency of heavy metal clean-up is critical, it is also important to know the level of anatomical impairment exposure to heavy metal may present on the plant in question. One of such plants is Chromolaena odorata. Being consistently used in heavy metal remediation, it is important to understudy its adaptive capabilities under heavy metal influence (Baker and Brooks 1989; Qureshi et al., 1995; Velasco-Alinsug et al., 2005; Singh et al., 2009). This is necessary to enhance knowledge of the plants' tolerance capacities.

The key means of gaseous exchange in vascular plants are the stomata. Any anatomical changes that affect the arrangement of conductance of the stomata will certainly impair plant gaseous exchange capacity, and the resultant effects are impaired metabolism and overall development. Heavy metal toxicity has been previously reported to affect epicuticular wax on leaf surfaces, which concomitantly affects stomatal opening (Frey et al., 2000; Singh et al., 2009). Reduction in the epidermal structure, reduction in cell size, as well as a rise in per unit area of stomata and trichomes with concurrent decrease in guard cells dimensions have been linked to heavy metal toxicity. These changes are not entirely reported for all plants, whether in the leaves, stem or roots; observable indicators of metal toxicant in plants vary at the structural and ultra-structural levels, from plant to plant. These variations are as a result of differences in interaction between the plants essential components and the toxic heavy metals (Singh and Sinha, 2004; Maruthi Sridhar et al., 2005; Katayama et al., 2013). Studying changes in leaf tissues also helps understand the process of metal accumulation and tolerance.

Hyperaccumualtor plants are known for their capacity to amass significantly higher concentrations of heavy metals, and at the same time, possess rapid growth rate and improved biomass accumulation (Marchiol et al., 2004). However, the limitation of metal uptake in different plant parts have been reported (Maruthi Sridhar et al., 2005). Li et al. (2006) also stated that most hyperaccumulator species produce little biomass and have slow growth rates. In order, therefore, to critically appraise plant performance as hyperaccumulators of heavy metals, an understanding of the anatomical, metabolic, and molecular mechanisms involved in heavy metal accumulation in different parts of the plant is therefore required. Given the fact that changes in plant anatomy can significantly alter plant metabolic activities, as well as molecular capacities in plant (Todeschini et al., 2011), studying these changes can help to understand the overall phytoremediation process (Maruthi Sridhar et al., 2005). This is the basis upon which the present study was executed.

\subsection{Methodology}

\subsection{Methods}

Top-layered garden soil $(0-10 \mathrm{~cm})$ was collected from ten random spots in the Botanic Garden of the Ugbowo Campus of the University of Benin and pooled together to form a composite soil sample. These were sun-dried to constant weight; and then $20 \mathrm{~kg}$ each was measured into experimental pots. The soil in each experimental pot was moistened with water to water holding capacity, which was earlier determined to be $190 \mathrm{ml} / \mathrm{kg}$ soil, and was made ready for use. The pots were then divided into 5 metal groups with 3 sub-groups each. Each entire group was then artificially polluted with Manganese $(\mathrm{Mn})$, Cadmium $(\mathrm{Cd})$, Copper $(\mathrm{Cu})$, Lead $(\mathrm{Pb})$ and $\mathrm{Zinc}(\mathrm{Zn})$ in their respective chloride compounds. Concentrations of the metals in the soil were initially based on their respective ecological screening value/benchmark (ESV) as documented by Efroymson et al. (1996). The ESV values for the 5 heavy metals (HM) were $50,4,100,50$ and $50 \mathrm{mg} / \mathrm{kg}$ respectively. Within each group, the respective heavy metals were applied in 3 concentrations of 1ESV, 3ESV and 5ESV. Heavy metal pollution in the pots were done by ensuring first that separate measured quantities of the respective heavy metals were dissolved in 3.38 litres of water with which each $20 \mathrm{~kg}$-soil was moistened again and thoroughly mixed. The control soil did not receive any heavy metal contamination. After another $24 \mathrm{hrs}$, equal sized stem cuttings of $C$. odorata $(2.0-2.3 \mathrm{~cm}$ in thickness, $30 \mathrm{~cm}$ in length) were planted vertically into the soil with a third of stem cutting buried into the soil. Two stem cuttings were planted per experimental pot. Since the experimental pots were exposed to prevailing weather condition, water holding capacity of each experimental pot was adjusted daily by adding $500 \mathrm{ml}$ of tap water ( $\mathrm{pH}$ 6.5-6.9). Adequate soil moisture was maintained at all times following standard methods 
(USDA, 2000). The experimental set up was maintained in the screen house for 6 months, after which foliar anatomical studies were conducted on freshly emerging leaves of the test plant.

\subsection{Physicochemical parameters}

Soils were dried at ambient temperature $\left(22-25^{\circ} \mathrm{C}\right)$ and were then crushed in a porcelain mortar and sieved through a $2-\mathrm{mm}$ (10 meshes) stainless sieve. They were then wrapped in aluminum foil papers and stored for subsequent analysis. For determination of soil $\mathrm{pH}, 20 \mathrm{ml}$ distilled water was introduced into $20 \mathrm{~g}$ of the soil and allowed to stand for 30 minutes. The mixture was stirred occasionally with a glass rod and the $\mathrm{pH}$ determined by inserting the $\mathrm{pH}$ meter (Model PHS-3C) into the suspension, and the soil conductivity read through a hand-held conductivity meter (HI 70039P, Hanna Instruments).

For determination of total organic carbon, $0.5 \mathrm{~g}$ of each air-dried soil sample was put into a conical flask and $2.5 \mathrm{ml}$ of $1 \mathrm{~N}$ potassium dichromate solution $\mathrm{K}_{2} \mathrm{Cr}_{2} \mathrm{O}_{7}$ was added and swirled gently to disperse the sample in the solution. Five millilitres $(5 \mathrm{ml})$ of concentrated tetraoxosulphate (VI) acid was added rapidly, into the flask and swirled gently until sample and reagents were mixed and finally swirled vigorously for about a minute. The flask was allowed to stand in a fume cupboard for 30 minutes. Five to ten (5 to 10 ) drops of the indicator were added and the solution titrated with $0.5 \mathrm{~N}$ $\mathrm{FeSO}_{4}$ to maroon colour. A blank determination was carried out to standardize the dichromate (Nelson and Sommers, 1982). TOC content was calculated as follows (Osuji and Nwoye, 2007):

$\operatorname{TOC}(\%)=\frac{\left(\mathrm{meqK}_{2} \mathrm{Cr}_{2} \mathrm{O}_{7}-\text { meqFeSO}_{4}\right) \times 0.003 \times 100 \times 1.3}{\text { weightofsample }(\mathrm{g})}$

where:

$m e q \mathrm{~K}_{2} \mathrm{Cr}_{2} \mathrm{O}_{7}=1 \mathrm{~N} \times 2.5 \mathrm{ml}$

meq $\mathrm{FeSO}_{4}=0.5 \mathrm{~N}$ x Volume of titrant in $\mathrm{ml}$

$0.03=$ Milliequivalent weight of carbon

$1.30=$ Correction factor

Nitrogen in the soil was determined by Kjeldahl digestion method. For the determination of the, $10 \mathrm{~g}$ of soil was weighed into a $250 \mathrm{ml}$ plastic bottle. $100 \mathrm{ml}$ of $\left(0.05 \mathrm{M} \mathrm{HCI}\right.$ in $\left.0.05 \mathrm{M} \mathrm{H}_{2} \mathrm{SO}_{4}\right)$ was added, stopper and then shaken for 30 minutes in mechanical shaker. The mixture was filtered through Whatman filter paper No.42and then, $\mathrm{Fe}, \mathrm{Cu}, \mathrm{Mn}, \mathrm{Zn}, \mathrm{Cd}, \mathrm{Cr}, \mathrm{Pb}, \mathrm{Ni}$ and $\mathrm{V}$ were determined in the filtrate by Atomic Absorption Spectrometry (Bray and Kurtz, 1945a, b; SSSA, 1971).

Heavy metal accumulated in plant stem, roots and leaves were also determined accordingly after 6 months. This was done by removing plant from soil and carefully washing off the attached soil and decries. The plants were sun-dried and each plant separated into stem, leaves and roots. Each part was crushed and grounded to powder before determination of heavy metals in the plant parts was carried out. Soil physicochemical parameters of soil were then determined prior to usage of the soil according to standard procedures (Bray and Kurtz, 1945a, b; SSSA, 1971; Nelson and Sommers, 1982; Osuji and Nwoye, 2007; Nasir et al., 2015). All physicochemical analyses were conducted in 3 replicates.

\subsection{Anatomical assessment}

The foliar epidermal characteristics of Chromolaena odorata was used for the study. Voucher specimens were deposited at the University of Lagos Plant Antomy Laboratory, Lagos State, Nigeria; and were investigated by means of light microscopy following the methodology of foliar epidermal morphological described by Ahmad (1976), Akhil and Subhan (1997), Kadiri et al. (2011), Kadiri and Ayodele (2003), leaf architecture terminologies follow Dilcher (1974) and Hickey (1973). Leaf epidermal preparations involved cutting one to five centimeters square portions from the standard median portion of the leaf laminar near the mid-rib and then swelled by boiling in water for twenty thirty minutes. The leaf pieces were later soaked in concentrated trioxonitrate $(\mathrm{V})$ acid $\left(\mathrm{HNO}_{3}\right)$ in capped specimen bottles for $24 \mathrm{~h}$ to macerate the mesophyll. Tissue disintegration was indicated by bubbles, and the epidermises were transferred into Petri- dishes containing water for cleansing and then, epidermises were separated with forceps and mounting needles. Tissue debris was cleared off the epidermises with fine hair brush and washed in several changes of water. Drops of different grades of ethanol: $50 \%, 70 \%, 75 \%$ up to $100 \%$ were added in turn to harden the cells. Preparations were 
later stained with Safranin O in $50 \%$ alcohol for about five minutes before mounting in glycerine on a glass slide. The epidermises were mounted on a glass slide with upper surfaces facing up and then covered with cover-slips and ringed with nail varnish to prevent dehydration.

Representative samples of leaf, stem and root were obtained for anatomical evaluations. Free hand transverse sections were made using a razor blade and taken through an alcohol series (as $30 \%$ and $50 \%$ alcohol). The samples were subsequently stained with $1 \%$ safranin in $50 \%$ ethanol. Stained material was mounted on glass slides using glycerin and Photomicrographs were taken. Other vegetative anatomical studies take after the methods of Bhandari and Mukhopadhyay (1997), Cutler (2005) and Radford (1967). Slides were examined with top view light microscopes at x100 and x400. All measurements in light microscope (LM) were made using a calibrated eyepiece micrometer with $\times 40$ objective. From each species 5 cells and stomata were randomly selected for measurement. Three replications were done for this measurement. Stomata index was calculated using the formulae of Stace (1965):

Stomata index $=\frac{\text { Stomata number } x 100}{\text { weightof sampleCell number per unit area }+\operatorname{stomata} \text { number }(g)}$

A morphological study for the leaf epidermal surfaces was carried out. Qualitative characters are; stomata type, epidermal type and cell shape patterns. Quantitative characters are epidermal cell length and width, number of epidermal cells per field of view, epidermal cell wall thickness and stomata length. All measurements were made using the light microscope at magnification (x 400, x100) using micrometer eyepiece. Statistical analyses of data were performed using SPSS $®$ version 20.0. A single factor analysis of variances was used to analyse data having assumed homogeneity of the entire experimental plot when soils were pooled before use. Least significant differences were used to separate treatment means at $95 \%$ confidence limit.

\subsection{Results and Discussion}

The physico-chemical condition of the soil before application of heavy metal contaminants has been presented (Table 1). Soil pH was 5.97, with significant increased iron content $(1011.92 \mathrm{mg} / \mathrm{kg})$. There was significant heavy metal accumulation in plant parts after 6 months of exposure. Generally, rhizoaccumulation of the respective heavy metals was noticeably more prominent than metal accumulation via stem and leaves (Table 2). Manganese was the most accumulated heavy metal in all plant parts $(9.22-17.86 \mathrm{mg} / \mathrm{kg})$, compared to $\mathrm{Cd}(0.85-1.66 \mathrm{mg} / \mathrm{kg})$.

Table 1: Physico-chemical properties of soil before contamination. These are background mean concentrations $(n=5)($ mean \pm S.E.M).

\begin{tabular}{ll}
\hline Parameters & $\begin{array}{l}\text { Mean } \pm \text { SEM } \\
(\mathrm{n}=3)\end{array}$ \\
\hline $\mathrm{pH}$ & $5.97 \pm 0.67$ \\
Electric conductivity $(\mu \mathrm{s} / \mathrm{cm})$ & $301.21 \pm 23.01$ \\
Total organic carbon $(\%)$ & $0.49 \pm 0.09$ \\
Total Nitrogen $(\%)$ & $4.18 \pm 1.06$ \\
Exchangeable acidity $(\mathrm{meq} / 100 \mathrm{~g})$ & $0.22 \pm 0.08$ \\
$\mathrm{Na}(\mathrm{meq} / 100 \mathrm{~g})$ & $10.90 \pm 2.11$ \\
$\mathrm{~K}(\mathrm{meq} / 100 \mathrm{~g})$ & $1.48 \pm 0.62$ \\
$\mathrm{Ca}(\mathrm{meq} / 100 \mathrm{~g})$ & $14.32 \pm 3.10$ \\
$\mathrm{Mg}(\mathrm{meq} / 100 \mathrm{~g})$ & $12.01 \pm 3.22$ \\
$\mathrm{Heavy} \mathrm{metals}$ & \\
$\mathrm{Fe}(\mathrm{mg} / \mathrm{kg})$ & $1011.92 \pm 73.38$ \\
$\mathrm{Cd}(\mathrm{mg} / \mathrm{kg})$ & $<0.001$ \\
$\mathrm{Mn}(\mathrm{mg} / \mathrm{kg})$ & $17.03 \pm 3.22$ \\
$\mathrm{~Pb}(\mathrm{mg} / \mathrm{kg})$ & $0.03 \pm 0.01$ \\
$\mathrm{Cu}(\mathrm{mg} / \mathrm{kg})$ & $3.93 \pm 0.01$ \\
$\mathrm{Zn}(\mathrm{mg} / \mathrm{kg})$ & $30.12 \pm 3.06$ \\
\hline
\end{tabular}


Table 2: Heavy metal concentrations (mean \pm SD) in plant part after 6 months

\begin{tabular}{|c|c|c|c|c|c|}
\hline \multirow{2}{*}{$\begin{array}{l}\text { Heavy } \\
\text { Metals }\end{array}$} & \multicolumn{3}{|c|}{ Total heavy metal concentrations (mg/kg DW) } & \multirow[t]{2}{*}{ P-value } & \multirow[t]{2}{*}{$\operatorname{LSD}(0.05)$} \\
\hline & Leaves & Stem & Root & & \\
\hline $\mathrm{Mn}+1 \mathrm{ESV}$ & $12.65 \pm 2.12$ & $10.38 \pm 2.04$ & $16.07 \pm 3.84$ & 0.429 & 4.17 \\
\hline$M n+3 E S V$ & $12.23 \pm 1.93$ & $10.51 \pm 1.32$ & $17.86 \pm 4.18$ & 0.096 & 6.33 \\
\hline $\mathrm{Mn}+5 \mathrm{ESV}$ & $11.53 \pm 2.55$ & $9.22 \pm 0.98$ & $13.36 \pm 2.23$ & 0.218 & 4.92 \\
\hline $\mathrm{Pb}+1 \mathrm{ESV}$ & $2.85 \pm 0.73$ & $3.28 \pm 0.06$ & $5.93 \pm 1.37$ & $<0.001$ & 1.05 \\
\hline $\mathrm{Pb}+3 \mathrm{ESV}$ & $2.12 \pm 0.83$ & $3.78 \pm 1.98$ & $6.23 \pm 1.47$ & 0.117 & 4.52 \\
\hline $\mathrm{Pb}+5 \mathrm{ESV}$ & $2.44 \pm 1.16$ & $4.37 \pm 1.32$ & $5.59 \pm 0.94$ & 0.026 & 3.58 \\
\hline $\mathrm{Cu}+1 \mathrm{ESV}$ & $5.82 \pm 0.84$ & $7.87 \pm 0.93$ & $7.52 \pm 2.11$ & 0.428 & 4.31 \\
\hline $\mathrm{Cu}+3 \mathrm{ESV}$ & $6.21 \pm 1.53$ & $4.75 \pm 0.36$ & $5.99 \pm 1.30$ & 0.375 & 3.06 \\
\hline $\mathrm{Cu}+5 \mathrm{ESV}$ & $6.02 \pm 1.15$ & $6.17 \pm 1.46$ & $6.39 \pm 1.32$ & 0.739 & 2.97 \\
\hline $\mathrm{Cd}+1 \mathrm{ESV}$ & $0.85 \pm 0.16$ & $1.06 \pm 0.65$ & $1.42 \pm 0.76$ & 0.522 & 0.69 \\
\hline $\mathrm{Cd}+3 \mathrm{ESV}$ & $1.05 \pm 0.38$ & $1.66 \pm 0.47$ & $1.60 \pm 0.35$ & 0.041 & 0.99 \\
\hline $\mathrm{Cd}+5 \mathrm{ESV}$ & $1.09 \pm 0.19$ & $1.56 \pm 0.45$ & $1.47 \pm 0.37$ & 0.669 & 1.06 \\
\hline $\mathrm{Zn}+1 \mathrm{ESV}$ & $3.20 \pm 0.01$ & $4.71 \pm 0.89$ & $9.33 \pm 1.47$ & $<0.001$ & 2.17 \\
\hline $\mathrm{Zn}+3 \mathrm{ESV}$ & $2.81 \pm 0.06$ & $4.18 \pm 0.16$ & $15.19 \pm 1.48$ & $<0.001$ & 4.44 \\
\hline $\mathrm{Zn}+5 \mathrm{ESV}$ & $3.85 \pm 0.11$ & $4.49 \pm 1.11$ & $11.13 \pm 1.04$ & $<0.001$ & 5.29 \\
\hline Control & NA & NA & NA & NA & NA \\
\hline p-value & $<0.001$ & $<0.001$ & $<0.001$ & - & - \\
\hline $\operatorname{LSD}(0.05)$ & 4.97 & 5.48 & 4.66 & - & - \\
\hline
\end{tabular}

Changes in leaf epidermal parameters of Chromolaena odorata have been presented on Plates $1-9$ and on Tables $3-8$. It is important to state that all stem cuttings survived after 6 months in all metal concentrations. Significant changes in number of stomata in the upper epidermis of plant leaf was reported $(\mathrm{p}<0.05)$. Although there were 254 stomata $\mathrm{mm}^{-2}$ in the control leaves, these values increased to values between 239 and 324 stomata $\mathrm{mm}^{-2}$ in the leaves of $\mathrm{Zn}$-exposed plants (Table 3) and 270 - 353 stomata $\mathrm{mm}^{-2}$ in $\mathrm{Cd}$ and $\mathrm{Mn}$-exposed plant leaves respectively (Table 4). Stomatal structures of $\mathrm{Cu}$ and $\mathrm{Mn}$ have been presented on Plates $1-9$.

Significant reduction in upper epidermal stomatal length $(20.1-24.5 \mu \mathrm{m})$ was reported in Cdexposed plant leaves, compared to $32.5 \mu \mathrm{m}$ in the control (Table 4, Plates 13 - 16). There was evidence of wavy anticlinal walls in the leaves of Cd-exposed plants (Plate 14). No significant changes in upper epidermal stomatal length compared to the control was reported in the other HMexposed plant leaves.

There were more stomata in the lower epidermis of $\mathrm{Zn}$-exposed plants $\left(22-26 \mathrm{~mm}^{-2}\right)$, compared to the control $\left(14 \mathrm{~mm}^{-2}\right)$. However, no significant changes in lower epidermal stomata number per squared millimeter was reported for $\mathrm{Cu}, \mathrm{Cd}, \mathrm{Pb}$ and $\mathrm{Mn}$-exposed plants ( $\mathrm{p}>0.05$ ). These foliar epidermal sections have been presented on Plates $17-32$. Notably, length of lower epidermal stomata was not affected by HM concentrations, compared to the control.

The effects of HM concentrations on stem anatomical characteristics of the test plant showed highly significant decrease in stem parenchyma thickness when compared with the control $(\mathrm{p}<0.01)$ (Table 5 - 6). Parenchyma thickness of HM-exposed plants ranged from $46.37-49.53 \mu \mathrm{m}$ in $\mathrm{Pb}$ and $\mathrm{Zn}-$ exposed plants, compared to $79.23 \mu \mathrm{m}$ in the control (Table 5). Stem parenchyma thickness of test plant in Cd-polluted soils was $29.71-40.52 \mu \mathrm{m}$ (Table 4, Plate 17 - 22). Increases in vascular bundle thickness $(\mathrm{p}<0.01)$ was reported in HM-exposed plants compared to the control. Increased xylem thickness was reported in plants exposed to higher levels of $\mathrm{Pb}$ and $\mathrm{Zn}$. However, significant reductions in the same parameter were reported for plants exposed to higher levels of $\mathrm{Cu}, \mathrm{Cd}$ and $\mathrm{Mn}$ (Tables 5 - 6).

Plant exposure to heavy metal concentrations significantly impaired root anatomical parameters of Chromolaena odorata (Tables 7 and 8; Plates $21-31$ ).HMs did not significantly affect the thickness of root pith $(\mathrm{p}>0.05)$. Significant increases $(\mathrm{p}<0.01)$ due to $\mathrm{Zn}$ exposure were recorded for xylem 
thickness $(139.34-184.10 \mu \mathrm{m})$, compared to the control $(99.23 \mu \mathrm{m})$; for the other HM-exposed plants other than $\mathrm{Pb}+5 \mathrm{ESV}$-exposed plants, no significant changes in xylem thickness was observed.

Table 3: Changes in leaf epidermal parameters of Chromolaena odorata under experimental stress at

\begin{tabular}{|c|c|c|c|c|c|c|c|c|c|c|}
\hline & $\begin{array}{l}\text { Stomatal } \\
\text { parameter }\end{array}$ & Ctrl & $\begin{array}{l}\mathrm{Pb}+ \\
1 \mathrm{ESV}\end{array}$ & $\begin{array}{l}\mathrm{Pb} \quad+ \\
3 \mathrm{ESV}\end{array}$ & $\begin{array}{l}\mathrm{Pb} \mathrm{+} \\
5 \mathrm{ESV}\end{array}$ & $\begin{array}{l}\mathrm{Zn+} \\
1 \mathrm{ESV}\end{array}$ & $\begin{array}{l}\text { Zn + } \\
3 \mathrm{ESV}\end{array}$ & $\begin{array}{l}\mathrm{Zn} \mathrm{+} \\
5 \mathrm{ESV}\end{array}$ & p-value & $\operatorname{LSD}(0.05)$ \\
\hline \multirow[t]{4}{*}{$\begin{array}{l}\text { Upper } \\
\text { epidermis }\end{array}$} & Number $\left(\mathrm{mm}^{-2}\right)$ & $\begin{array}{l}254.2 \\
\pm 12.1\end{array}$ & $\begin{array}{l}277.5 \\
\pm 12.8\end{array}$ & $\begin{array}{l}249.1 \\
\pm 12.40\end{array}$ & $\begin{array}{l}249.5 \\
+12.0\end{array}$ & $\begin{array}{l}324.5 \\
+137\end{array}$ & $\begin{array}{l}282.3 \\
+13.00\end{array}$ & $\begin{array}{l}239.11 \\
+13.40\end{array}$ & 0.016 & 33.64 \\
\hline & Length $(\mu \mathrm{m})$ & $\begin{array}{l}32.5 \\
\pm 2.50\end{array}$ & $\begin{array}{l}26.5 \\
\pm 2.64\end{array}$ & $\begin{array}{l}29 \\
\pm 2.90\end{array}$ & $\begin{array}{l}25.5 \\
\pm 2.40\end{array}$ & $\begin{array}{l}21.5 \\
\pm 2.40\end{array}$ & $\begin{array}{l}32 \\
\pm 3.10\end{array}$ & $\begin{array}{l}28.35 \\
\pm 2.60\end{array}$ & 0.025 & 8.66 \\
\hline & Breadth $(\mu \mathrm{m})$ & $\begin{array}{l}18.3 \\
\pm 2.50\end{array}$ & $\begin{array}{r}15.5 \\
\pm 3.7\end{array}$ & $\begin{array}{l}16.4 \\
\pm 4.11\end{array}$ & $\begin{array}{l}15.5 \\
\pm 4.12\end{array}$ & $\begin{array}{l}13.4 \\
\pm 3.58\end{array}$ & $\begin{array}{l}27.3 \\
\pm 2.27\end{array}$ & $\begin{array}{l}16.51 \\
\pm 4.13\end{array}$ & $<0.001$ & 1.64 \\
\hline & Thickness $(\mu \mathrm{m})$ & $\begin{array}{l}5.2 \\
\pm 3.20\end{array}$ & $\begin{array}{l}5.1 \\
\pm 3.1\end{array}$ & $\begin{array}{l}3.75 \\
\pm 2.11\end{array}$ & $\begin{array}{l}2.5 \\
\pm 1.50\end{array}$ & $\begin{array}{l}5.1 \\
\pm 2.11\end{array}$ & $\begin{array}{l}5.2 \\
\pm 2.31\end{array}$ & $\begin{array}{l}5.24 \\
\pm 2.44\end{array}$ & 0.047 & 1.33 \\
\hline \multirow[t]{4}{*}{$\begin{array}{l}\text { Lower } \\
\text { epidermis }\end{array}$} & Number $\left(\mathrm{mm}^{-2}\right)$ & $\begin{array}{l}14.5 \\
\pm 2.4\end{array}$ & $\begin{array}{l}18.4 \\
\pm 2.6\end{array}$ & $\begin{array}{l}16.1 \\
\pm 2.11\end{array}$ & $\begin{array}{l}18.2 \\
\pm 3.70\end{array}$ & $\begin{array}{l}17.5 \\
\pm 4.2\end{array}$ & $\begin{array}{l}22.5 \\
\pm 2.10\end{array}$ & $\begin{array}{l}26.3 \\
\pm 5.80\end{array}$ & 0.022 & 6.63 \\
\hline & Length $(\mu \mathrm{m})$ & $\begin{array}{l}13.5 \\
\pm 1.40\end{array}$ & $\begin{array}{l}11.5 \\
\pm 2.6\end{array}$ & $\begin{array}{l}14.5 \\
\pm 7.41\end{array}$ & $\begin{array}{l}14 \\
\pm 6.00\end{array}$ & $\begin{array}{l}14 \\
\pm 6.00\end{array}$ & $\begin{array}{l}16.5 \\
\pm 7.50\end{array}$ & $\begin{array}{l}15.5 \\
\pm 6.33\end{array}$ & 0.058 & 5.18 \\
\hline & Breadth $(\mu \mathrm{m})$ & $\begin{array}{l}5.5 \\
\pm 2.50\end{array}$ & $\begin{array}{l}2.5 \\
\pm 1.4\end{array}$ & $\begin{array}{l}3.1 \\
\pm 1.21\end{array}$ & $\begin{array}{l}4.25 \\
\pm 1.43\end{array}$ & $\begin{array}{l}5.2 \\
\pm 2.00\end{array}$ & $\begin{array}{l}2.5 \\
\pm 2.00\end{array}$ & $\begin{array}{l}2.5 \\
\pm 2.00\end{array}$ & 0.047 & 1.12 \\
\hline & Thickness $(\mu \mathrm{m})$ & $\begin{array}{l}5.2 \\
\pm 3.20\end{array}$ & $\begin{array}{l}5.1 \\
\pm 3.1\end{array}$ & $\begin{array}{l}3.75 \\
\pm 2.44\end{array}$ & $\begin{array}{l}2.5 \\
\pm 2.00\end{array}$ & $\begin{array}{l}5.3 \\
\pm 3.10\end{array}$ & $\begin{array}{l}5.2 \\
\pm 3.12\end{array}$ & $\begin{array}{l}5.1 \\
\pm 3.55\end{array}$ & 0.018 & 1.32 \\
\hline
\end{tabular}

Table 4: Changes in leaf epidermal parameters of Chromolaena odorata under experimental stress at 6 months after sowing (mean \pm S.E.M)

\begin{tabular}{|c|c|c|c|c|c|c|c|c|c|c|c|c|c|}
\hline & $\begin{array}{l}\text { Stomatal } \\
\text { parameter }\end{array}$ & Ctrl & $\begin{array}{l}\mathrm{Cu}+ \\
1 \mathrm{ESV} \\
\end{array}$ & $\begin{array}{l}\mathrm{Cu}+ \\
3 \mathrm{ESV} \\
\end{array}$ & $\begin{array}{l}\mathrm{Cu}+ \\
5 \mathrm{ESV} \\
\end{array}$ & $\begin{array}{l}\mathrm{Cd}+ \\
1 \mathrm{ESV} \\
\end{array}$ & $\begin{array}{l}\mathrm{Cd}+ \\
\text { 3ESV } \\
\end{array}$ & $\begin{array}{l}\mathrm{Cd}+ \\
5 \mathrm{ESV} \\
\end{array}$ & $\begin{array}{l}\mathrm{Mn}+ \\
1 \mathrm{ESV} \\
\end{array}$ & $\begin{array}{l}\text { Mn+ } \\
\text { 3ESV }\end{array}$ & $\begin{array}{l}\mathrm{Mn+} \\
\text { 5ESV } \\
\end{array}$ & $\begin{array}{l}\mathrm{p}- \\
\text { value }\end{array}$ & $\operatorname{LSD}(0.05)$ \\
\hline \multirow[t]{4}{*}{$\begin{array}{l}\text { Upper } \\
\text { epidermis }\end{array}$} & Number $\left(\mathrm{mm}^{-2}\right)$ & $\begin{array}{l}254.2 \\
\pm 12.1\end{array}$ & $\begin{array}{l}258.2 \\
\pm 10.11\end{array}$ & $\begin{array}{l}332.3 \\
\pm 11.64\end{array}$ & $\begin{array}{l}314.5 \\
\pm 10.48\end{array}$ & $\begin{array}{l}307.5 \\
\pm 10.31\end{array}$ & $\begin{array}{l}285.1 \\
\pm 11.40\end{array}$ & $\begin{array}{l}270.4 \\
\pm 11.81\end{array}$ & $\begin{array}{l}323.2 \\
\pm 11.84\end{array}$ & $\begin{array}{l}326.5 \\
\pm 13.20\end{array}$ & $\begin{array}{l}353.5 \\
\pm 13.4\end{array}$ & 0.014 & 33.6 \\
\hline & Length $(\mu \mathrm{m})$ & $\begin{array}{l}32.5 \\
\pm 2.50\end{array}$ & $\begin{array}{l}32.5 \\
\pm 2.87\end{array}$ & $\begin{array}{l}37.2 \\
\pm 2.70\end{array}$ & $\begin{array}{l}33.3 \\
\pm 3.50\end{array}$ & $\begin{array}{l}24.5 \\
\pm 2.48\end{array}$ & $\begin{array}{l}20.1 \\
\pm 2.0\end{array}$ & $\begin{array}{l}23.5 \\
\pm 3.1\end{array}$ & $\begin{array}{l}30.1 \\
\pm 3.4\end{array}$ & $\begin{array}{l}29.5 \\
\pm 2.10\end{array}$ & $\begin{array}{l}31.3 \\
\pm 3.20\end{array}$ & 0.035 & 8.66 \\
\hline & Breadth $(\mu \mathrm{m})$ & $\begin{array}{l}18.3 \\
\pm 2.50\end{array}$ & $\begin{array}{l}12.5 \\
\pm 2.18\end{array}$ & $\begin{array}{l}11.3 \\
\pm 2.30\end{array}$ & $\begin{array}{l}20.2 \\
\pm 1.92\end{array}$ & $\begin{array}{l}17.5 \\
\pm 2.73\end{array}$ & $\begin{array}{l}16.5 \\
\pm 2.84\end{array}$ & $\begin{array}{l}18.2 \\
\pm 1.77\end{array}$ & $\begin{array}{l}16.4 \\
\pm 1.84\end{array}$ & $\begin{array}{l}20.5 \\
\pm 1.54\end{array}$ & $\begin{array}{l}16.2 \\
\pm 1.23\end{array}$ & 0.009 & 1.64 \\
\hline & $\begin{array}{l}\text { Thickness } \\
(\mu \mathrm{m})\end{array}$ & $\begin{array}{l}5.2 \\
\pm 3.20\end{array}$ & $\begin{array}{l}2.5 \\
\pm 1.50\end{array}$ & $\begin{array}{l}5.4 \\
\pm 2.64\end{array}$ & $\begin{array}{l}5.2 \\
\pm 2.77\end{array}$ & $\begin{array}{l}5.3 \\
\pm 2.87\end{array}$ & $\begin{array}{l}5.3 \\
\pm 2.87\end{array}$ & $\begin{array}{l}5.4 \\
\pm 2.89\end{array}$ & $\begin{array}{l}5.2 \\
\pm 2.80\end{array}$ & $\begin{array}{l}5.4 \\
\pm 2.81\end{array}$ & $\begin{array}{l}5.1 \\
\pm 2.82\end{array}$ & 0.011 & 1.33 \\
\hline \multirow[t]{4}{*}{$\begin{array}{l}\text { Lower } \\
\text { epidermis }\end{array}$} & Number $\left(\mathrm{mm}^{-2}\right)$ & $\begin{array}{l}14.5 \\
\pm 2.4\end{array}$ & $\begin{array}{l}19.4 \\
\pm 6.41\end{array}$ & $\begin{array}{l}19.2 \\
\pm 7.72\end{array}$ & $\begin{array}{l}16.4 \\
\pm 3.40\end{array}$ & $\begin{array}{l}19.5 \\
\pm 5.41\end{array}$ & $\begin{array}{l}18.5 \\
\pm 6.11\end{array}$ & $\begin{array}{l}19.5 \\
\pm 5.12\end{array}$ & $\begin{array}{l}23.1 \\
\pm 7.00\end{array}$ & $\begin{array}{l}18.5 \\
\pm 8.23\end{array}$ & $\begin{array}{l}18.5 \\
\pm 3.10\end{array}$ & 0.028 & 7.63 \\
\hline & Length $(\mu \mathrm{m})$ & $\begin{array}{l}13.5 \\
\pm 1.40\end{array}$ & $\begin{array}{l}16.1 \\
\pm 7.11\end{array}$ & $\begin{array}{l}14.1 \\
\pm 6.20\end{array}$ & $\begin{array}{l}14.2 \\
\pm 11.40\end{array}$ & $\begin{array}{l}14.5 \\
\pm 1.30\end{array}$ & $\begin{array}{l}13.5 \\
\pm 10.42\end{array}$ & $\begin{array}{l}13.1 \\
\pm 11.35\end{array}$ & $\begin{array}{l}13.5 \\
\pm 11.24\end{array}$ & $\begin{array}{l}13.5 \\
\pm 11.24\end{array}$ & $\begin{array}{l}14.5 \\
\pm 11.26\end{array}$ & 0.132 & 5.18 \\
\hline & Breadth $(\mu \mathrm{m})$ & $\begin{array}{l}5.5 \\
\pm 2.50\end{array}$ & $\begin{array}{l}4.75 \\
\pm 2.50\end{array}$ & $\begin{array}{l}3.25 \\
\pm 1.22\end{array}$ & $\begin{array}{l}3.5 \\
\pm 1.31\end{array}$ & $\begin{array}{l}4.5 \\
\pm 2.10\end{array}$ & $\begin{array}{l}3.3 \\
\pm 1.71\end{array}$ & $\begin{array}{l}2.5 \\
\pm 1.42\end{array}$ & $\begin{array}{l}3.25 \\
\pm 2.93\end{array}$ & $\begin{array}{l}2.5 \\
\pm 1.10\end{array}$ & $\begin{array}{l}2.5 \\
\pm 1.10\end{array}$ & 0.008 & 1.12 \\
\hline & Thickness $(\mu \mathrm{m})$ & $\begin{array}{l}5.2 \\
\pm 3.20 \\
\end{array}$ & $\begin{array}{l}2.5 \\
\pm 2.21\end{array}$ & $\begin{array}{l}5.3 \\
\pm 2.41\end{array}$ & $\begin{array}{l}5.2 \\
\pm 2.42 \\
\end{array}$ & $\begin{array}{l}5.4 \\
\pm 2.33\end{array}$ & $\begin{array}{l}5.3 \\
\pm 3.42\end{array}$ & $\begin{array}{l}5.1 \\
\pm 3.11\end{array}$ & $\begin{array}{l}5.2 \\
\pm 3.42 \\
\end{array}$ & $\begin{array}{l}5.3 \\
\pm 3.11\end{array}$ & $\begin{array}{l}5.2 \\
\pm 3.42\end{array}$ & $<0.001$ & 1.3 \\
\hline
\end{tabular}

Table 5: Changes in stem anatomical parameters of Chromolaena odorata under experimental stress

\begin{tabular}{|c|c|c|c|c|c|c|c|c|c|}
\hline $\begin{array}{l}\text { Stomatal } \\
\text { parameter }\end{array}$ & Ctrl & $\begin{array}{l}\mathrm{Pb}+ \\
1 \mathrm{ESV}\end{array}$ & $\begin{array}{l}\mathrm{Pb}+ \\
3 \mathrm{ESV}\end{array}$ & $\begin{array}{l}\mathrm{Pb} \quad+ \\
5 \mathrm{ESV}\end{array}$ & $\begin{array}{l}\mathrm{Zn}+ \\
1 \mathrm{ESV}\end{array}$ & $\begin{array}{l}\mathrm{Zn} \mathrm{+} \\
3 \mathrm{ESV}\end{array}$ & $\begin{array}{l}\mathrm{Zn} \mathrm{+} \\
5 \mathrm{ESV}\end{array}$ & $\begin{array}{l}\mathrm{p}- \\
\text { value }\end{array}$ & $\operatorname{LSD}(0.05)$ \\
\hline Parenchyma & 79.23 & 49.51 & 47.62 & 49.53 & 49.54 & 49.53 & 46.37 & $<0.001$ & 11.56 \\
\hline $\begin{array}{l}\text { thickness } \\
(\mu \mathrm{m})\end{array}$ & \pm 2.01 & \pm 1.11 & \pm 1.76 & \pm 1.85 & \pm 1.15 & \pm 1.62 & \pm 0.28 & & \\
\hline Vascular & 495.1 & 732.6 & 752.4 & 732.6 & 633.6 & 673.2 & 608.8 & $<0.001$ & 109.69 \\
\hline $\begin{array}{l}\text { Bundle } \\
\text { thickness } \\
(\mu \mathrm{m})\end{array}$ & \pm 6.45 & \pm 12.77 & \pm 8.72 & \pm 6.47 & \pm 12.00 & \pm 12.03 & \pm 12.13 & & \\
\hline $\begin{array}{l}\text { Epidermal } \\
\text { thickness } \\
(\mu \mathrm{m})\end{array}$ & $\begin{array}{l}49.54 \\
\pm 4.32\end{array}$ & $\begin{array}{l}45.53 \\
\pm 1.45\end{array}$ & $\begin{array}{l}23.76 \\
\pm 1.01\end{array}$ & $\begin{array}{l}49.51 \\
\pm 2.34\end{array}$ & $\begin{array}{l}49.52 \\
\pm 1.15\end{array}$ & $\begin{array}{l}19.83 \\
\pm 0.98\end{array}$ & $\begin{array}{l}19.81 \\
\pm 0.99\end{array}$ & 0.006 & 9.35 \\
\hline $\begin{array}{l}\text { Xylem } \\
\text { thickness } \\
(\mu \mathrm{m})\end{array}$ & $\begin{array}{l}69.31 \\
\pm 12.3\end{array}$ & $\begin{array}{l}49.52 \\
\pm 13.20\end{array}$ & $\begin{array}{l}49.53 \\
\pm 4.64\end{array}$ & $\begin{array}{l}88.8 \\
\pm 11.80\end{array}$ & $\begin{array}{l}69.31 \\
\pm 4.34\end{array}$ & $\begin{array}{l}69.34 \\
\pm 3.87\end{array}$ & $\begin{array}{l}89.13 \\
\pm 4.94\end{array}$ & 0.036 & 13.2 \\
\hline $\begin{array}{l}\text { Cortex } \\
\text { thickness } \\
(\mu \mathrm{m})\end{array}$ & $\begin{array}{l}514.8 \\
\pm 7.84\end{array}$ & $\begin{array}{l}574.2 \\
\pm 7.30\end{array}$ & $\begin{array}{l}554.4 \\
\pm 3.11\end{array}$ & $\begin{array}{l}495.3 \\
\pm 12.22\end{array}$ & $\begin{array}{l}475.2 \\
\pm 2.65\end{array}$ & $\begin{array}{l}594.2 \\
\pm 6.34\end{array}$ & $\begin{array}{l}495.3 \\
\pm 7.45\end{array}$ & 0.006 & 26.46 \\
\hline
\end{tabular}




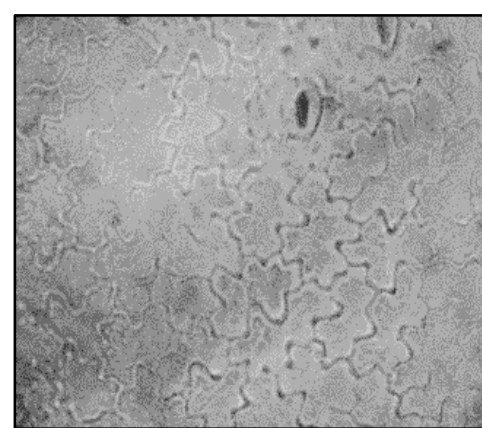

1

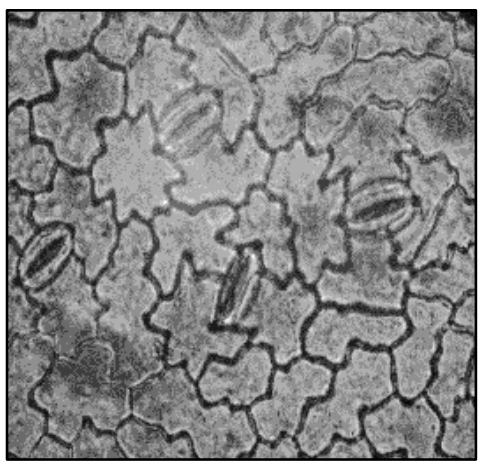

4

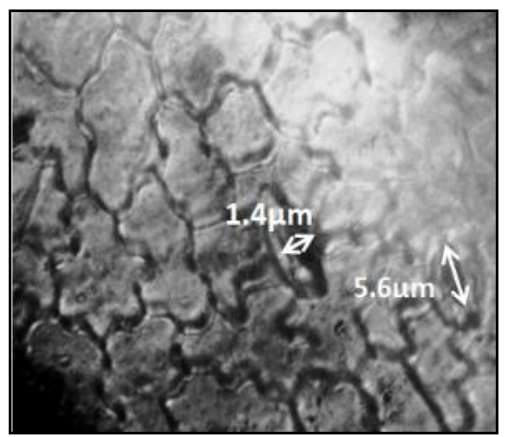

7

\section{Leaf Epidermal Cell}

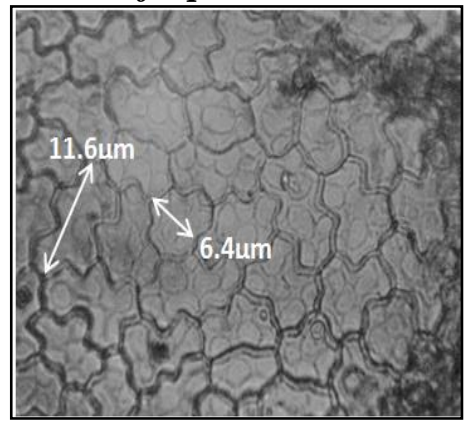

2

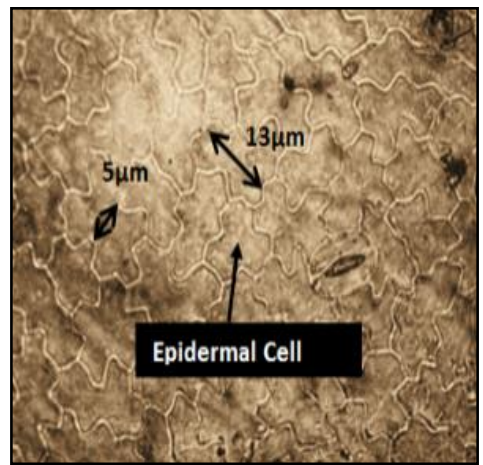

5

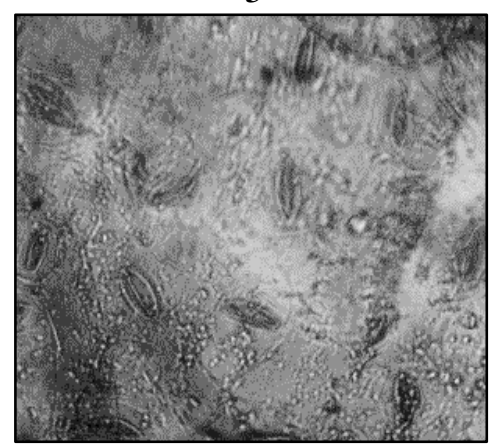

8

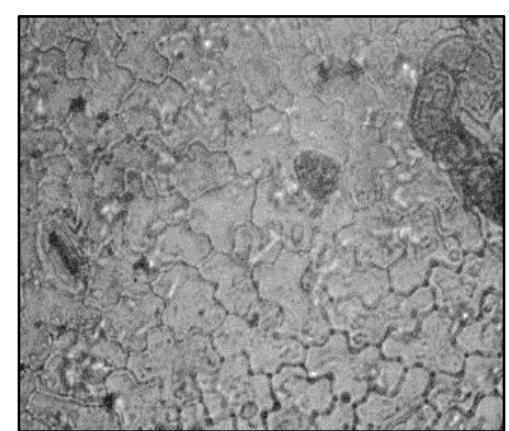

3

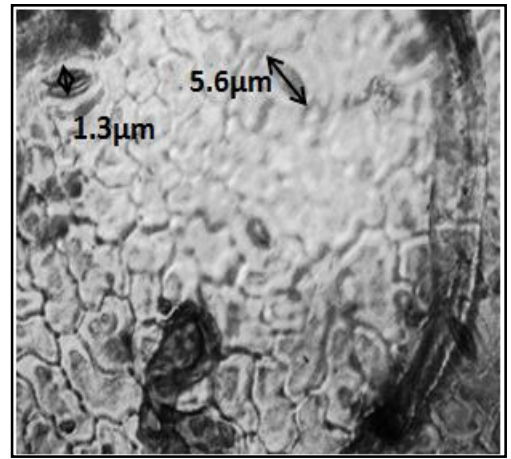

6

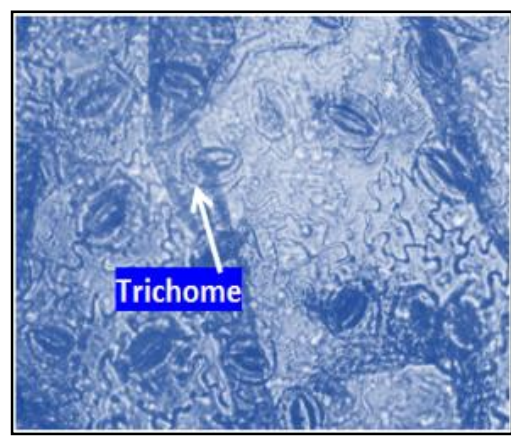

9

Plate 1: Leaf upper epidermis of $C$. odorata exposed to $\mathrm{Pb}+1 \mathrm{ESV}$ (mag. x400)

Plate 2: Leaf upper lower epidermis of $C$. odorata exposed to Pb+3ESV (mag. x400)

Plate 3: Leaf upper epidermis of $C$. odorata exposed to Zn+1ESV (mag. x400)

Plate 4: Leaf upper epidermis of $C$. odorata exposed to Zn+3ESV (mag. x400)

Plate 5: Leaf upper epidermis of $C$. odorata exposed to $\mathrm{Cu}+1 \mathrm{ESV}$ (mag. x400)

Plate 6: Leaf lower epidermis of $C$. odorata exposed to $\mathrm{Cu}+3 \mathrm{ESV}$ (mag. x400)

Plate 7: Leaf lower epidermis of $C$. odorata exposed to $\mathrm{Cu}+5 \mathrm{ESV}$ (mag. x400)

Plate 8: Leaf lower epidermis of $C$. odorata exposed to Cd+1ESV (mag. x400)

Plate 9: Leaf lower epidermis of $C$. odorata exposed to Cd+3ESV (mag. x400)

Table 6: Changes in stem anatomical parameters of Chromolaena odorata under experimental stress at 6 months after sowing

\begin{tabular}{|c|c|c|c|c|c|c|c|c|c|c|c|c|}
\hline $\begin{array}{l}\text { Stomatal } \\
\text { parameter }\end{array}$ & Ctrl & $\begin{array}{l}\mathrm{Cu}+ \\
1 \mathrm{ESV}\end{array}$ & $\begin{array}{l}\mathrm{Cu}+ \\
3 \mathrm{ESV}\end{array}$ & $\begin{array}{l}\mathrm{Cu}+ \\
5 \mathrm{ESV}\end{array}$ & $\begin{array}{l}\mathrm{Cd}+ \\
1 \mathrm{ESV}\end{array}$ & $\begin{array}{l}\mathrm{Cd}+ \\
3 \mathrm{ESV}\end{array}$ & $\begin{array}{l}\mathrm{Cd}+ \\
5 \mathrm{ESV}\end{array}$ & $\begin{array}{l}\mathrm{Mn+} \\
1 \mathrm{ESV}\end{array}$ & $\begin{array}{l}\mathrm{Mn}+ \\
\text { 3ESV }\end{array}$ & $\begin{array}{l}\text { Mn+ } \\
5 \mathrm{ESV}\end{array}$ & $\begin{array}{l}\mathrm{p}- \\
\text { value }\end{array}$ & $\operatorname{LSD}(0.05)$ \\
\hline $\begin{array}{l}\text { Parenchyma } \\
\text { thickness }(\mu \mathrm{m})\end{array}$ & $\begin{array}{l}79.23 \\
\pm 2.01\end{array}$ & $\begin{array}{l}31.68 \\
\pm 6.42\end{array}$ & $\begin{array}{l}23.76 \\
\pm 7.67\end{array}$ & $\begin{array}{l}43.2 \\
\pm 2.24\end{array}$ & $\begin{array}{l}37.62 \\
\pm 9.67\end{array}$ & $\begin{array}{l}29.71 \\
\pm 7.67\end{array}$ & $\begin{array}{l}40.52 \\
\pm 2.77\end{array}$ & $\begin{array}{l}49.51 \\
\pm 5.64\end{array}$ & $\begin{array}{l}49.54 \\
\pm 2.45\end{array}$ & $\begin{array}{l}25.74 \\
\pm 12.25\end{array}$ & 0.008 & 11.56 \\
\hline $\begin{array}{l}\text { Vascular } \\
\text { Bundle } \\
\text { thickness }(\mu \mathrm{m})\end{array}$ & $\begin{array}{l}495.1 \\
\pm 6.45\end{array}$ & $\begin{array}{l}455.4 \\
\pm 12.43\end{array}$ & $\begin{array}{l}428.6 \\
\pm 5.21\end{array}$ & $\begin{array}{l}336.6 \\
\pm 4.11\end{array}$ & $\begin{array}{l}514.8 \\
\pm 5.24\end{array}$ & $\begin{array}{l}336.6 \\
\pm 3.21\end{array}$ & $\begin{array}{l}732.6 \\
\pm 1.50\end{array}$ & $\begin{array}{l}594.3 \\
\pm 5.77\end{array}$ & $\begin{array}{l}514.53 \\
\pm 6.72\end{array}$ & $\begin{array}{l}496.2 \\
\pm 5.01\end{array}$ & 0.011 & 109.69 \\
\hline $\begin{array}{l}\text { Epidermal } \\
\text { thickness }(\mu \mathrm{m})\end{array}$ & $\begin{array}{l}49.54 \\
\pm 4.32\end{array}$ & $\begin{array}{l}49.74 \\
\pm 8.22\end{array}$ & $\begin{array}{l}49.81 \\
\pm 1.34\end{array}$ & $\begin{array}{l}49.51 \\
\pm 5.41\end{array}$ & $\begin{array}{l}47.72 \\
\pm 5.32\end{array}$ & $\begin{array}{l}49.54 \\
\pm 17.20\end{array}$ & $\begin{array}{l}49.52 \\
\pm 3.40\end{array}$ & $\begin{array}{l}19.83 \\
\pm 2.45\end{array}$ & $\begin{array}{l}19.81 \\
\pm 5.43\end{array}$ & $\begin{array}{l}31.68 \\
\pm 1.85\end{array}$ & 0.041 & 9.35 \\
\hline $\begin{array}{l}\text { Xylem } \\
\text { thickness }(\mu \mathrm{m})\end{array}$ & $\begin{array}{l}69.31 \\
\pm 12.3\end{array}$ & $\begin{array}{l}69.34 \\
\pm 6.11\end{array}$ & $\begin{array}{l}46.41 \\
\pm 6.71\end{array}$ & $\begin{array}{l}49.53 \\
\pm 7.24\end{array}$ & $\begin{array}{l}49.12 \\
\pm 3.44\end{array}$ & $\begin{array}{l}49.51 \\
\pm 4.23\end{array}$ & $\begin{array}{l}29.82 \\
\pm 7.89\end{array}$ & $\begin{array}{l}45.3 \\
\pm 8.23\end{array}$ & $\begin{array}{l}43.55 \\
\pm 5.43\end{array}$ & $\begin{array}{l}49.5 \\
\pm 4.32\end{array}$ & 0.038 & 13.2 \\
\hline $\begin{array}{l}\text { Cortex } \\
\text { thickness }(\mu \mathrm{m})\end{array}$ & $\begin{array}{l}514.8 \\
\pm 7.84\end{array}$ & $\begin{array}{l}574.2 \\
\pm 25.02\end{array}$ & $\begin{array}{l}633.6 \\
\pm 2.33\end{array}$ & $\begin{array}{l}415.8 \\
\pm 4.87\end{array}$ & $\begin{array}{l}376.2 \\
\pm 16.83\end{array}$ & $\begin{array}{l}475.2 \\
\pm 27.11\end{array}$ & $\begin{array}{l}475.2 \\
\pm 7.11\end{array}$ & $\begin{array}{l}495.2 \\
\pm 4.34\end{array}$ & $\begin{array}{l}633.6 \\
\pm 5.12\end{array}$ & $\begin{array}{l}297.4 \\
\pm 2.34\end{array}$ & $<0.001$ & 26.46 \\
\hline
\end{tabular}


Table 7: Changes in root anatomical parameters of Chromolaena odorata under experimental stress at 6 months after sowing (mean \pm S.E.M)

\begin{tabular}{|c|c|c|c|c|c|c|c|c|c|}
\hline Stomatal parameter & Ctrl & $\begin{array}{l}\mathrm{Pb}+ \\
1 \mathrm{ESV}\end{array}$ & $\begin{array}{l}\mathrm{Pb}+ \\
3 \mathrm{ESV}\end{array}$ & $\begin{array}{l}\mathrm{Pb}+ \\
5 \mathrm{ESV}\end{array}$ & $\begin{array}{l}\mathrm{Zn}+ \\
1 \mathrm{ESV}\end{array}$ & $\begin{array}{l}\mathrm{Zn} \mathrm{+} \\
3 \mathrm{ESV}\end{array}$ & $\begin{array}{l}\mathrm{Zn} \quad+ \\
5 \mathrm{ESV}\end{array}$ & $\begin{array}{l}\mathrm{p}- \\
\text { value }\end{array}$ & $\operatorname{LSD}(0.05)$ \\
\hline Pith & $\begin{array}{l}336.6 \\
\pm 17.60\end{array}$ & $\begin{array}{l}297.2 \\
\pm 12.20\end{array}$ & $\begin{array}{l}297.1 \\
\pm 10.50\end{array}$ & $\begin{array}{l}315.4 \\
\pm 17.10\end{array}$ & $\begin{array}{l}295.3 \\
\pm 16.50\end{array}$ & $\begin{array}{l}297.2 \\
\pm 15.40\end{array}$ & $\begin{array}{l}297.1 \\
\pm 14.40\end{array}$ & 0.138 & 89.16 \\
\hline $\begin{array}{l}\text { Xylem } \\
(\mu \mathrm{m})\end{array}$ & $\begin{array}{l}99.23 \\
\pm 5.11\end{array}$ & $\begin{array}{l}99.41 \\
\pm 5.90\end{array}$ & $\begin{array}{l}79.22 \\
\pm 4.40\end{array}$ & $\begin{array}{l}148.5 \\
\pm 7.80\end{array}$ & $\begin{array}{l}184.1 \\
\pm 15.50\end{array}$ & $\begin{array}{l}139.34 \\
\pm 5.40\end{array}$ & $\begin{array}{l}148.5 \\
\pm 10.50\end{array}$ & 0.011 & 42.36 \\
\hline $\begin{array}{l}\text { Vascular Bundle } \\
\text { thickness }(\mu \mathrm{m})\end{array}$ & $\begin{array}{l}455.4 \\
\pm 12.10\end{array}$ & $\begin{array}{l}633.6 \\
\pm 13.70\end{array}$ & $\begin{array}{l}554.4 \\
\pm 13.00\end{array}$ & $\begin{array}{l}613.8 \\
\pm 15.40\end{array}$ & $\begin{array}{l}633.6 \\
\pm 15.70\end{array}$ & $\begin{array}{l}455.4 \\
\pm 14.10\end{array}$ & $\begin{array}{l}415.8 \\
\pm 14.00\end{array}$ & 0.001 & 25.76 \\
\hline $\begin{array}{l}\text { Epidermal thickness } \\
(\mu \mathrm{m})\end{array}$ & $\begin{array}{l}108.8 \\
\pm 8.70\end{array}$ & $\begin{array}{l}128.7 \\
\pm 9.90\end{array}$ & $\begin{array}{l}139.2 \\
\pm 9.80\end{array}$ & $\begin{array}{l}169.5 \\
\pm 9.20\end{array}$ & $\begin{array}{l}198.1 \\
\pm 9.10\end{array}$ & $\begin{array}{l}128.7 \\
\pm 8.20\end{array}$ & $\begin{array}{l}199.7 \\
\pm 9.20\end{array}$ & 0.039 & 16.34 \\
\hline $\begin{array}{l}\text { Cortex } \\
(\mu \mathrm{m})\end{array}$ & $\begin{array}{l}594.1 \\
\pm 12.01 \\
\end{array}$ & $\begin{array}{l}497.2 \\
\pm 10.11 \\
\end{array}$ & $\begin{array}{l}514.8 \\
\pm 12.34 \\
\end{array}$ & $\begin{array}{l}297.3 \\
\pm 3.20 \\
\end{array}$ & $\begin{array}{l}495.4 \\
\pm 11.81 \\
\end{array}$ & $\begin{array}{l}653.4 \\
\pm 12.70 \\
\end{array}$ & $\begin{array}{l}732.6 \\
\pm 14.00 \\
\end{array}$ & 0.002 & 120.35 \\
\hline
\end{tabular}

Table 8: Changes in root anatomical parameters of Chromolaena odorata under experimental stress

\begin{tabular}{|c|c|c|c|c|c|c|c|c|c|c|c|c|}
\hline $\begin{array}{l}\text { Stomatal } \\
\text { parameter }\end{array}$ & Ctrl & $\begin{array}{l}\mathrm{Cu}+ \\
1 \mathrm{ESV}\end{array}$ & $\begin{array}{l}\mathrm{Cu}+ \\
3 \mathrm{ESV}\end{array}$ & $\begin{array}{l}\mathrm{Cu}+ \\
5 \mathrm{ESV}\end{array}$ & $\begin{array}{l}\mathrm{Cd}+ \\
1 \mathrm{ESV}\end{array}$ & $\begin{array}{l}\mathrm{Cd}+ \\
3 \mathrm{ESV}\end{array}$ & $\begin{array}{l}\mathrm{Cd}+ \\
5 \mathrm{ESV}\end{array}$ & $\begin{array}{l}\mathrm{Mn+} \\
1 \mathrm{ESV}\end{array}$ & $\begin{array}{l}\mathrm{Mn+} \\
\text { 3ESV }\end{array}$ & $\begin{array}{l}\mathrm{Mn+} \\
\text { 5ESV }\end{array}$ & $\begin{array}{l}\mathrm{p}- \\
\text { value }\end{array}$ & $\operatorname{LSD}(0.05)$ \\
\hline $\begin{array}{l}\text { Pith thickness } \\
(\mu \mathrm{m})\end{array}$ & $\begin{array}{l}336.6 \\
\pm 17.60\end{array}$ & $\begin{array}{l}356.2 \\
\pm 15.90\end{array}$ & $\begin{array}{l}297.2 \\
\pm 16.00\end{array}$ & $\begin{array}{l}297.2 \\
\pm 11.20\end{array}$ & $\begin{array}{l}316.8 \\
\pm 15.5\end{array}$ & $\begin{array}{l}346.1 \\
\pm 15.70\end{array}$ & $\begin{array}{l}356.4 \\
\pm 17.50\end{array}$ & $\begin{array}{l}297.4 \\
\pm 12.20\end{array}$ & $\begin{array}{l}355.1 \\
\pm 18.40\end{array}$ & $\begin{array}{l}356.4 \\
\pm 17.70\end{array}$ & 0.043 & 89.06 \\
\hline Xylem & 99.23 & 99.12 & 79.27 & 49.51 & 99.83 & 99.32 & 49.51 & 99.52 & 108.8 & 99.21 & 0.017 & 12.36 \\
\hline thickness $(\mu \mathrm{m})$ & \pm 5.11 & \pm 5.70 & \pm 4.10 & \pm 3.00 & \pm 5.90 & \pm 5.80 & \pm 4.20 & \pm 5.60 & \pm 7.80 & \pm 5.00 & & \\
\hline $\begin{array}{l}\text { Vascular } \\
\text { Bundle } \\
\text { thickness }(\mu \mathrm{m})\end{array}$ & $\begin{array}{l}455.4 \\
\pm 12.10\end{array}$ & $\begin{array}{l}495.3 \\
\pm 14.80\end{array}$ & $\begin{array}{l}415.8 \\
\pm 14.71\end{array}$ & $\begin{array}{l}514.8 \\
\pm 15.50\end{array}$ & $\begin{array}{l}475.2 \\
\pm 14.90\end{array}$ & $\begin{array}{l}633.6 \\
\pm 16.10\end{array}$ & $\begin{array}{l}495.4 \\
\pm 14.30\end{array}$ & $\begin{array}{l}336.6 \\
\pm 13.20\end{array}$ & $\begin{array}{l}129.6 \\
\pm 10.10\end{array}$ & $\begin{array}{l}455.4 \\
\pm 14.80\end{array}$ & 0.009 & 25.76 \\
\hline $\begin{array}{l}\text { Epidermal } \\
\text { thickness }(\mu \mathrm{m})\end{array}$ & $\begin{array}{l}108.8 \\
\pm 8.70\end{array}$ & $\begin{array}{l}198.4 \\
\pm 9.00\end{array}$ & $\begin{array}{l}199.4 \\
\pm 9.30\end{array}$ & $\begin{array}{l}198.1 \\
\pm 9.11\end{array}$ & $\begin{array}{l}198.1 \\
\pm 9.30\end{array}$ & $\begin{array}{l}198.3 \\
\pm 9.12\end{array}$ & $\begin{array}{l}198.4 \\
\pm 9.54\end{array}$ & $\begin{array}{l}119.3 \\
\pm 9.73\end{array}$ & $\begin{array}{l}138.8 \\
\pm 8.01\end{array}$ & $\begin{array}{l}199.8 \\
\pm 8.87\end{array}$ & 0.041 & 16.34 \\
\hline $\begin{array}{l}\text { Cortex } \\
\text { thickness }(\mu \mathrm{m})\end{array}$ & $\begin{array}{l}594.1 \\
\pm 12.01\end{array}$ & $\begin{array}{l}554.4 \\
\pm 15.31\end{array}$ & $\begin{array}{l}534.6 \\
\pm 15.31\end{array}$ & $\begin{array}{l}594.4 \\
\pm 15.42\end{array}$ & $\begin{array}{l}495.2 \\
\pm 14.70\end{array}$ & $\begin{array}{l}574.2 \\
\pm 15.88\end{array}$ & $\begin{array}{l}693.3 \\
\pm 16.41\end{array}$ & $\begin{array}{l}356.4 \\
\pm 3.84\end{array}$ & $\begin{array}{l}633.6 \\
\pm 16.78\end{array}$ & $\begin{array}{l}495.2 \\
\pm 14.30\end{array}$ & 0.015 & 120.67 \\
\hline
\end{tabular}

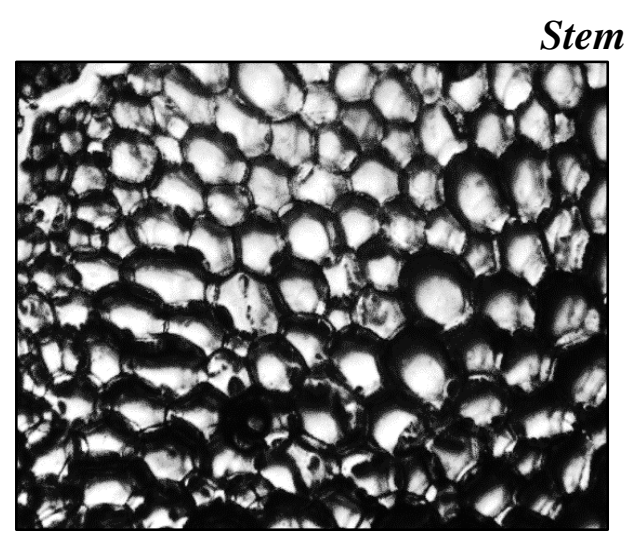

10

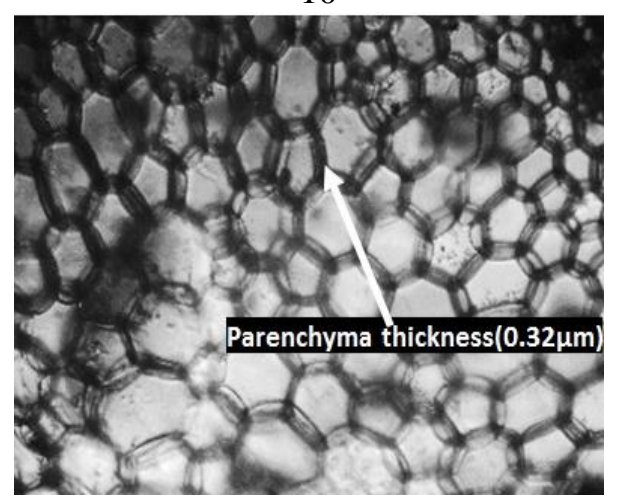

12

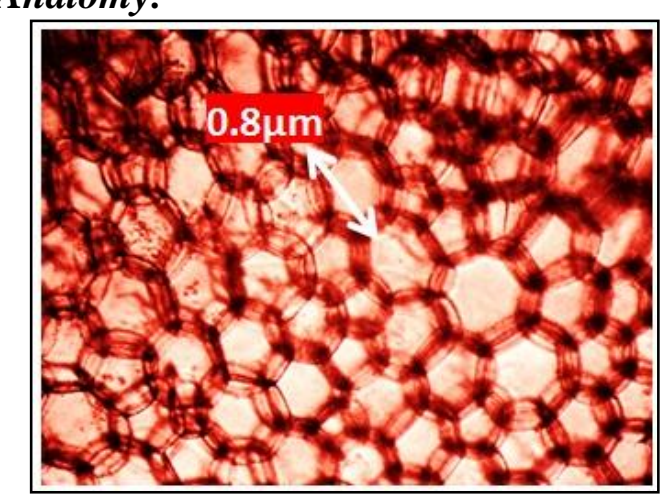

11

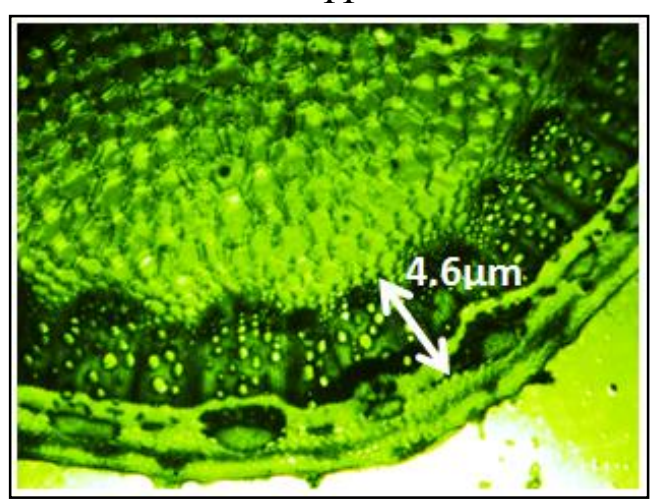

13

Plate 10: Transverse section of stem of $C$. odorata exposed to Cd+1ESV (mag. X100) Plate 11: Transverse section of stem of $C$. odorata in the control treatment (mag. X100) Plate 13: Transverse section of stem of $C$. odorata exposed to Cu+1ESV (mag. x100) Plate 14: Transverse section of stem of $C$. odorata exposed to Cu+3ESV (mag. x100) 


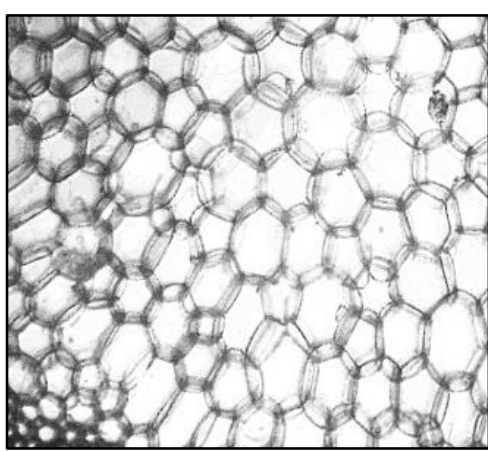

15

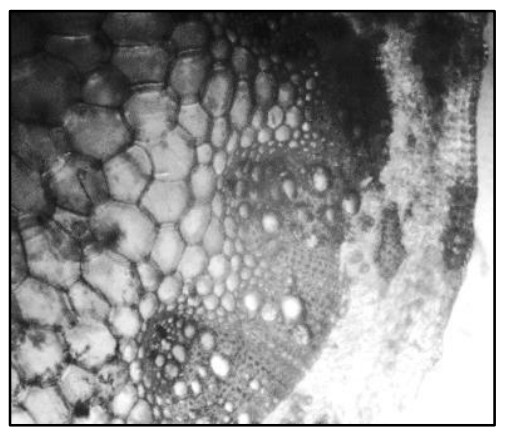

18

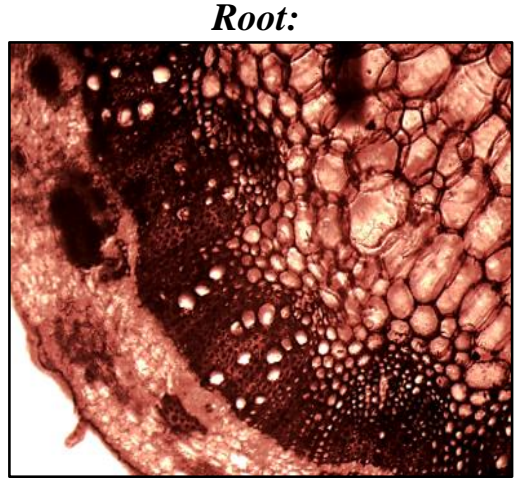

16

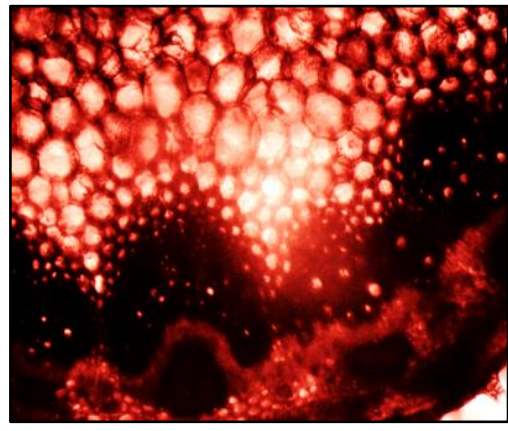

19

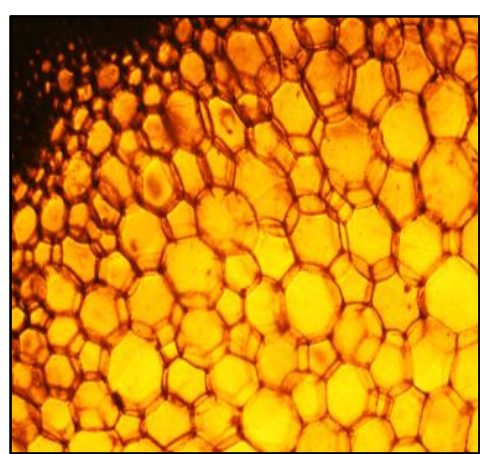

17

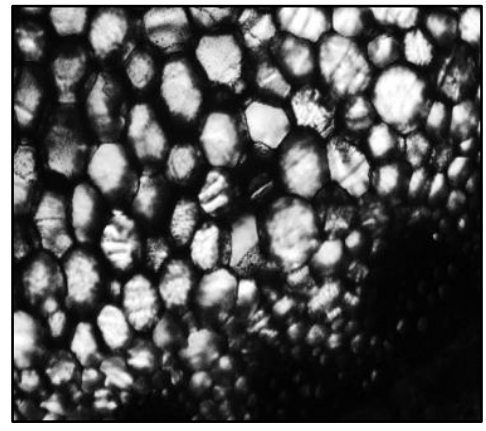

20

Plate 15: Transverse section of root of $C$. odorata exposed to Pb+1ESV (mag. x100)

Plate 16: Transverse section of root of $C$. odorata exposed to Pb+3ESV (mag. x100)

Plate 17: Transverse section of root of $C$. odorata exposed to Zn+1ESV (mag. x100)

Plate 18: Transverse section of root of $C$. odorata exposed to Zn+3ESV (mag. x100)

Plate 19: Transverse section of root of $C$. odorata exposed to Mn+3ESV (mag. x100)

Plate 20: Transverse section of root of $C$. odorata exposed to Mn+5ESV (mag. x100)

Heavy metals have antagonistic effects on the physiological and biochemical function of plants, culminating in reduced growth rate, alterations in morphological features as well as altered metabolism. The present study showed that accumulations of heavy metals by plants have significant impact on foliar, stem and root anatomy. Paivoke (1983) reported significant reduction in thickness of Tansy leaves obtained from polluted sites from Ada Huja. He also reported thickness reduction of leaf mesophyll, palisade parenchyma and upper and lower epidermis in plant. Omosun et al. (2008) also reported reduced cell size of the epidermis and parenchyma tissue due to $\mathrm{Cu}$ toxicity.

As reported in the study, the possession of thicker parenchyma cell wall in HM-exposed plants compared to the control was noted. This suggests that this may just indicate the possibility that $C$. odorata may have deposited HMs in its stem/xylem cell walls. It has been suggested that the cell membrane as well as the cell wall interface might be metal tolerance due to a large amount of metals stored there. In highly concentrated heavy metal surroundings, some plants increase polysaccharide production such as pectin. This is done in order to boost the ability of the cell wall to bind metals (Colzi et al., 2011; Pelloux et al., 2007).

With respect to metal accumulation, different mechanisms exist and various mechanisms exist in different plant species. Frey et al. (2000) reported Zn sequestration via epidermal cell vacuoles in $T$. caerulescens. In the leaves of A. halleri. Zn is sequestered in the mesophyll cells (Kupper et al., 2000; Zhao et al., 2000; Sarret et al., 2002). It is suggested from this study the presence of a regulatory mechanism in leaf mesophyll protoplast particularly the plasma membrane.

Being insoluble when inside the plant, the metal often form sulphate, phosphate or carbonate precipitate which immobilizes them in the extracellular and intracellular compartments (Raskin et al., 1997). Unless the metal ion is transported as a non-cationic metal chelate, apoplastic transport is further limited by the high cation exchange capacity of cell walls (Raskin et al., 1997). In the 
extracellular pathway, solutes must be taken up via the roots before entering the xylem (Tester and Leigh, 2001).

The intracellular movements of HMs likely occur in the xylem and the presence of the selectively permeable membrane makes it highly regulated (Gaymard, 1998). However, most metal ions enter plant cells via specific metal ion carriers (Bubb and Lester, 1991). Some harmful heavy metals such as $\mathrm{Cd}$ compete for the same transmembranic carrier used by a micronutrient heavy metal. This may partly explain their ability to enter the cell against a concentration gradient.

\subsection{Conclusions}

The negative impact of accumulated heavy metals on leaf, stem and folia anatomy has been reported in the study. Given the important role plant anatomical features play in physiological functions including photosynthesis and nutrient absorption and assimilation, it is possible that obvious effects of heavy metal-induced growth inhibition, decreased water potential, and efflux of cations, alterations in membrane functions, inhibition of photosynthesis, respiration, and altered metabolism may have resulted from compromised plant anatomy. It is suggested therefore that the extent of anatomical changes on plant functions as a consequence of heavy metal exposure be investigated.

\section{Acknowledgement}

Biotechnology and Environmental Sustainability Research Group, University of Benin, is highly acknowledged.

\section{Funding}

This study was supported by Tertiary Education Trust Fund and Needs Assessment.

\section{References}

Ahmad, K. J. (1976). Epidermal studies in some species of Hygrophila and Dyschoriste (Acanthaceae). Journal of Indian Botanical Society, 55, pp. 41 - 52.

Akhil, B. and Subhan, C. N. (1997). Foliar epidermal characters in twelve species of Cinnamomum Schaeffer (Lauraceae) from Northeastern India. Phytomorphology, 47, pp. 127 -134.

Baker, A. J .M. and Brooks, R. R. (1989). Terrestrial higher plants which hyperaccumulate metallic elements - a review of their distribution ecology and phytochemistry. Biorecovery, 1, pp. 81-126.

Bhandari, J. B. and Mukhopadhyay. (1997). Morphological and Anatomical studies on Antrophyumcallifolium Bl. Phytomorphology, 47, pp. 155-160.

Bray, R. H. and Kurtz, L. T. (1945a). Soil chemical analysis. Soil Science, 59, pp. 39-45.

Bray, R. H. and Kurtz, L. T. (1945b). Determination of total organic and available form of phosphorus in soils. Soil Science, 59, pp. 45-49.

Bubb, J. M. and Lester, J. N. (1991).The Impact of Heavy Metals on Lowland Rivers and the Implications for Man and the Environment Science and Total Environment, 100, pp. 207-233.

Colzi, I., Doumett, S., Del Bubba, M., Fornaini, J., Arnetoli, M., Gabbrielli, R. and Gonnelli, C. (2011). On the role of the cell wall in the phenomenon of copper toler-ance in Silene. Environmental and Experimental Botany, 72, pp. 77-83.

Cutler, D. F. (2005). Design in plants. In: Collins, M. W., Atherton, M. A. and Bryant, J. A. (Eds). Nature and Design. Southampton, Boston: WIT Press, pp. 95-124.

Dilcher, D. L. (1974). Approaches to the Identification of Angiosperm Leaf Remains. Botanical Review, 4, pp. $1-157$. 
Efroymson, R. A., Will, M. E., Suter II, G. W. and Wooten, A. C. (1997). Toxicological Benchmarks for Screening Contaminants of Potential Concern for Effects on Terrestrial Plants: 1997 Revision. ES/ER/TM-85/R3.U.S. Department of Energy, Office of Environmental Management. 123p.

Frey, B., Keller, C. and Zierold, K. (2000). Distribution of Zn in functionally different leaf epidermal cells of the hyperaccumulator Thlaspicaerulescens. Plant Cell Environment, 23, pp. 675-687.

Gaymard, F. (1998). Identification and disruption of a plant shaker-like outward channel involved in $\mathrm{K}^{+}$release into the xylem sap. Cell, 94, pp. 647-655.

Hickey, L. J. (1973).Classification of architecture of dicotyledonous leaves. American Journal of Botany, 60, pp. 17-33.

Kadiri, A. B. and Ayodele, A. E. (2003). Comparative Leaf Micro-Morphological Characters of The Nigerian Species of Rauvolfia Linn., (Apocynaceae). Bioscience Research Communication, 15, pp. 35 -41 .

Kadiri, A. B., Ayodele, A. E., Olowokudejo, J. D. and Uchemefuna, D. (2011). Comparative Leaf Epidermal Morphology of five West African Species of Uapaca (Baill) Phyllanthaceae Proforma Euphorbiaceae. Nigerian Journal of Botany, 24, pp. 257 - 266.

Katayama, H., Banba, N., Sugimura, Y., Tatsumi, M., Kusakari, S., Oyama, H. and Nakahira, A. (2013). Subcellular compartmentation of strontium and zinc in mulberry idioblasts in relation to phytoremediation potential. Environmental and Experimental Botany, 85, pp. 30-35.

Kupper, H., Lombi, E. and Zhao, F. J. (2000). Cellular compartmentation of cadmium and zinc in relation to other elements in the hyperaccumulator Arabidopsis halleri. Planta, 212, pp. 75-84.

Li, T. Q., Yang, X. E., Yang, J. Y. and He, Z. L. (2006). Zn accumulation and subcellular distribution in the Zn hyperaccumulator Sedum alfrediiHance. Pedosphere, 16, pp. 616-623.

Marchiol, L., Assolari, S., Sacco, P. and Zerbi, G. (2004). Phytoextraction of heavy metals by canola (Brassica napus) and radish (Raphanussativus) grown on multicontaminated soil. Environmental Pollution, 132, pp. 21-27.

Maruthi Sridhar, B. B., Diehl, S. V., Han, F. X., Monts, D. L. and Su, Y. (2005). Anatomical changes due to uptake and accumulation of $\mathrm{Zn}$ and $\mathrm{Cd}$ in Indian mustard (Brassica juncea). Environmental and Experimental Botany, 54, pp. 131-141.

Nasir, R., Khan, M., Masab, M., Rehman, H. U., Rauf, N. U., Shahab, S., et al. (2015). Accumulation of Heavy Metals ( $\mathrm{Ni} \mathrm{Cu} \mathrm{Cd} \mathrm{Cr} \mathrm{Pb} \mathrm{Zn} \mathrm{Fe.} \mathrm{in} \mathrm{the} \mathrm{soil} \mathrm{water} \mathrm{and} \mathrm{plants} \mathrm{and} \mathrm{analysis} \mathrm{of} \mathrm{physico-}$ chemical parameters of soil and water Collected from Tanda Dam Kohat. Journal of Pharmacological Science and Resources, 7, pp. 89-97.

Nelson, D. W. and Sommers, L. E. (1982).Total carbon, organic carbon and organic matter. In: Methods of Soil Analysis Part II. ASA/SSSA, Madison WI. pp 539 - 579.

Omosun, G., Markson, A. A. and Mbanasor, O. (2008). Growth and anatomy of Amaranthus hybridus affected by different crude oil concentration. American Eurasian Journal of Science and Research, 3 , pp. $70-74$.

Osuji, L. C. and Nwoye, I. (2007). An appraisal on the impact of petroleum hydrocarbon on soil fertility: the Owaza experience. African Journal of Agricultural Research, 2, pp. 318 - 324.

Paivoke, H. (1983). The short term effect of zinc on growth anatomy and acid phosphate activity of pea seedlings. Annals of Botany, 20, pp. 307-309. 
Pelloux, J., Rusterucci, C. and Mellerowicz, E. J. (2007). New insights into pectin methyl-esterase structure and function. Trends in Plant Science, 12, pp. $267-277$.

Perfus-Barbeoch, L., Leonhardt, N., Vavasseur, A. and Forestier, C. (2002). Heavy metal toxicity: cadmium permeates through calcium channels and disturbs the plant water status. Plant Journal, 32, pp. 539-548.

Qureshi, J. A., Thurman, D. A., Hardwick, K. and Collin, H.A. (1995). Uptake and accumulation of zinc, lead and copper in zinc and lead tolerant Anthoxanthumodoratum L. New Phytology, 100, pp. 429-434.

Radford, P. J. (1967). Growth analysis formulae: their use and abuse. Crop Science, 7, pp. $171-175$.

Raskin, I., Smith, R. D. and Salt, D. E. (1997). Phytoremediation of metals: Using plants to remove pollutants from the environment. Current Opinion in Biotechnology, 8, pp. $221-226$.

Sarret, G., Saumitou-Laprade, P. and Bert, V. (2002). Forms of zinc accumulated in the hyperaccumulatorArabidopsis halleri. Plant Physiology, 130, pp. 1815-1826.

Singh, S., Thorat, V., Kaushik, C.P., Raj, K. and Eapen, S. (2009) Potential of Chromolaena odorata for phytoremediation of 137 Cs from solution and low level nuclear waste. Journal of Hazardous Material, 162, pp. 743-745.

SSSA (1971).Instrumental Methods for Analysis of Soil and Plant Tissue. Soil Science Society of America Corporated Wisconsin USA, pp. 27-32.

Stace, C. A. (1965). Cuticular studies as an aid to plant taxonomy. Bulletin of the British Museum (National History) Botany, 4, pp. 3 - 78.

Tester, M. and Leigh, R. A. (2001).Partitioning of nutrient transport processes in roots. Journal of Experimental Botany, 52, pp. 445-457.

Todeschini, V., Lingua, G., D’Agostino, G., Carniato, F., Roccotiello, E. and Berta, G. (2011). Effects of high $\mathrm{Zn}$ concentration on poplar leaves: a morphological and biochemical study. Environmental Experimental Botony, 71, pp. 50-56.

USDA (2000). United States Department of Agriculture. http//www.unitedsoybean.org/soystats2000/.

Velasco-Alinsug, M. P., Rivero, G. C. and Quibuyen, T. A. O. (2005). Isolation of mercury-binding peptides in vegetative parts of Chromolaena odorata. Zeitschrift fur Naturforschung, 60, pp. 252-259.

Zhao, F. J., Kupper, H. and Lombi, E. (2000). Cellular compartmentation of cadmium and zinc in relation to other elements in the hyperaccumulator Arabidopsis halleri. Planta, 212, pp. 75-84.

\section{Cite this article as:}

Omoregie G. O. and Ikhajiagbe B., 2021. Changes in Anatomical Features of Chromolaena Odorata during Phytoaccumulation of Heavy Metals. Nigerian Journal of Environmental Sciences and Technology, 5(2), pp. 365-376. https://doi.org/10.36263/nijest.2021.02.0285 